\title{
Experimental study of the control of operating modes of a plate feeder based on the frequency-controlled electric drive
}

\author{
Olimjon Toirov ${ }^{1, *}$, Sardor Urokov ${ }^{2}$, Utkir Mirkhonov ${ }^{3}$, Hadha Afrisal $^{4}$, and Dilnoza Jumaeva ${ }^{5}$ \\ ${ }^{1}$ Tashkent State Technical University, DSc., Prof. Head of the Department of Electrical machine, Tashkent, 100095, Uzbekistan \\ ${ }^{2}$ Tashkent State Technical University, Doctoral Student, Department of Electrical machine, Tashkent, 100095, Uzbekistan \\ ${ }^{3}$ Bukhara Engineering Technological Institute, Senior Lecturer, Doctoral Student, Department of Energy Audit, Bukhara, Uzbekistan \\ ${ }^{4}$ Universitas Diponegoro, Department of Electrical Engineering, Semarang, Indonesia \\ ${ }^{5}$ Institute of General and Inorganic Chemistry of the Academy of Sciences of the Republic of Uzbekistan, Tashkent, 100170, Uzbekistan
}

\begin{abstract}
An experimental study of the control of the operating modes of the plate feeder based on a frequency-controlled electric drive in the mining industry has been carried out. The graphs of measurements of the electrical parameters of the electric drive supplied from the frequency converter of the plastic feeder, instantaneous values of harmonic composition of voltage and current up to 50 harmonics, as well as changes in current and voltage harmonics over a period of 30 minutes were obtained. Measurement of oscillograms of voltage and current of each phase in operating mode and the moment of turning off and turning on the electric motor of the plastic feeder. The issues of control of starting modes of the plate feeder from frequency-controlled electric drives are considered. It has been determined that frequency start-up with the linear control law for the frequency of the plate feeder as a function of time and technological parameters are the most acceptable condition for starting modes.
\end{abstract}

\section{Introduction}

In the world, by improving the dynamic modes of operation of technological machines and mechanisms, elements of the electromechanical system with modern control devices, improving the elements of the electromechanical system, using control methods, energy-efficient technologies are being created in the mining and metallurgical industry. The main energy consumption in mining and metallurgical enterprises occurs in the process of excavation and ore preparation, which is more than $38 \%$ of the total energy consumption, including the processes of ore preparation account for at least $10 \%$ of world energy consumption [1-4].

The modern electric drive being the main power element for converting electrical energy into mechanical energy, consumes more than $60 \%$ of all generated energy in the world. The electric drives together with other technical devices acts as a means of regulation in technological complexes [1].

In world practice, the controlled electric drive is recognized as one of the most efficient energy-saving and resource-saving environmentally friendly technologies [2-3].

The outlined intensive introduction into operation of adjustable electric drives of mechanisms makes it possible to solve not only the problem of energy saving, but also resource saving.

The use of speed-controlled electric drives for various mechanisms of the mining and metallurgical industry will make it possible to create a new energy- saving technology, which saves not only electricity and material resources, but also ensures resource-saving [47].

Currently, widespread introduction of frequency converters for technological equipment of mining and metallurgical plants has begun, especially on conveyors, feeders, smoke exhausters, blowers, compressors and other electric drives of technological equipment, which gives positive results in energy and resource saving [89].

As noted, the main technological mechanisms and installations are crushers, pumps for various purposes, conveyors, feeders, mills, fans, blowers, blowers, compressors, smoke exhausters, etc., where the power element is an asynchronous or synchronous electric drive of various power [10-12]. Since most of the technological equipment is typical in the mining and metallurgical industry, it is possible to make a unified approach to further increase energy and resource conservation based on the use of variable frequency drives in technological mechanisms and installations.

In the mining industry, one of the most common types of continuous machines involved in ore preparation are transport belt conveyors and feeders [13, 14].

Plate feeders are used to transport bulk, highly abrasive materials in technological lines of metallurgical, mining, processing, cement and other industries. They are conveyors with a belt made of metal links, up to

\footnotetext{
Corresponding author: olimjontoirov@gmail.com
} 
Table 1. Experimental and passport data of the electric drive of the plate feeder supplied from the frequency converter.

\begin{tabular}{|c|c|c|c|c|c|c|c|c|}
\hline \multirow{3}{*}{ № } & \multicolumn{8}{|c|}{ Plate Feeder } \\
\hline & \multicolumn{2}{|c|}{ Parameters } & \multicolumn{4}{|c|}{ Experimental data } & \multicolumn{2}{|c|}{ Passport data } \\
\hline & & & Phase-A & Phase-B & Phase-C & Middle & Type & A093-12-86 \\
\hline 1 & Voltage, B & Up & 223 & 221 & 229 & 224 & Voltage, B & 380 \\
\hline 2 & Current, $\mathrm{A}$ & $\mathrm{A}$ & 37.48 & 37.15 & 37.62 & 37.62 & Rated current, $\mathrm{A}$ & 47 \\
\hline 3 & Active Power & $\mathrm{kW}$ & 3.845 & 3.695 & 3.963 & 11.50 & Engine power, $\mathrm{kW}$ & 25 \\
\hline 4 & Reactive Power & Kwar L & 7.421 & 7.332 & 7.649 & 22.40 & Efficiency & 0,83 \\
\hline 5 & Reactive Power & Kwar C & 0 & 0 & 0 & 0 & $\begin{array}{l}\text { Number of } \\
\text { revolutions }\end{array}$ & 730 \\
\hline 6 & Power Factor & $\cos \varphi$ & 0.46 & 0.45 & 0.46 & 0.46 & Frequency & 0,80 \\
\hline 7 & Frequency & $\mathrm{Hz}$ & 50 & 50 & 50 & 50 & $\begin{array}{c}\text { Frequency } \\
\text { Converter type }\end{array}$ & KEB \\
\hline 8 & Total Power & $\mathrm{kVA}$ & 8.36 & 8.21 & 8.61 & 25.18 & Power FC, kW & 50 \\
\hline
\end{tabular}

$2400 \mathrm{~mm}$ wide, up to $18 \mathrm{~m}$ long and with a capacity of up to $1700 \mathrm{~m}^{3} / \mathrm{h}[15]$.

The operating mode of the conveyor drive motors is continuous with rare starts and stops. At the same time, an important general requirement for electric drives of continuous transport mechanisms is to ensure smooth start-up, with reliable limitation of acceleration and jerk, braking and normal functioning in the operating mode [16-18].

Currently, in connection with the industrial development of reliable frequency converters based on thyristors and IGBT or IGCT transistors, the most effective is the construction of feeder control systems using frequency-controlled asynchronous electric drives. At the same time, the system of a frequency converter an asynchronous motor allows for the regulation of acceleration and speed, as well as a long-term operation of the drive at low speeds according to the conditions of the technological process, which in general simultaneously solves the issues of energy and resource saving [19,20]. However, it is of interest to solve a number of issues related to the start-up of an electric drive of feeders based on frequency converters.

At the same time, by increasing the energy efficiency of the feed installations, improving the control systems of electric drives, work is being done to reduce the consumption of electrical energy and, in turn, special attention is paid to the development of this industry.

The purpose of the study is to determine the control law of starting modes of a plate feeder from variable frequency drives, taking into account the technological process of ore preparation on the basis of experimental research.

\section{Research methods}

The research method of scientific work is the experimental method. On the basis of experimental research on real operating installations, the electrical parameters of the electric drive supplied from the frequency converter of the plastic feeder, the instantaneous values of the harmonic composition of voltage and current in the dynamic modes of the plate feeder were determined.
At the same time, the results of instrumental measurements of electric drives of equipment powered by frequency converters are of interest, for example, an electric drive of a plate feeder powered by a frequency converter (FC) with a power of $50 \mathrm{~kW}$ [4]. These measurements are shown in Table 1 and Fig. 1-7 - their graphs.

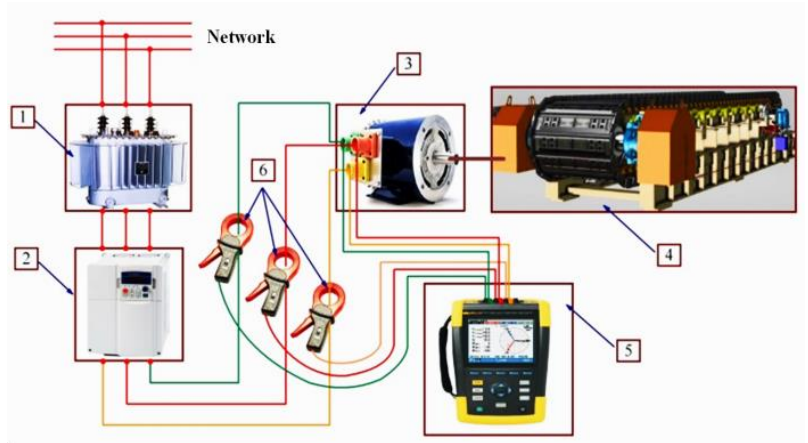

Fig. 1. Block diagram of a frequency controlled electric drive of a plastic feeder with connections by devices: 1 - transformer, 2 - frequency converter, 3 - asynchronous motor, 4 - plate feeder, 5 - three-phase energy quantity and quality analyzer, 6 current clamp for measuring alternating current.

Experimental measurements were carried out after the inverter before the engine using an AR-5 electric analyzer.

Table 1 shows the experimental and passport data of the electric drive of the plate feeder supplied from the frequency converter, as voltage (V), current (A), active power (W), reactive power: inductive P.L (var), capacitive P.C (var), and supply frequency (Hz), apparent power (VA).

In Fig. 2 these data are presented in graphical form for a period of time of 30 minutes. 


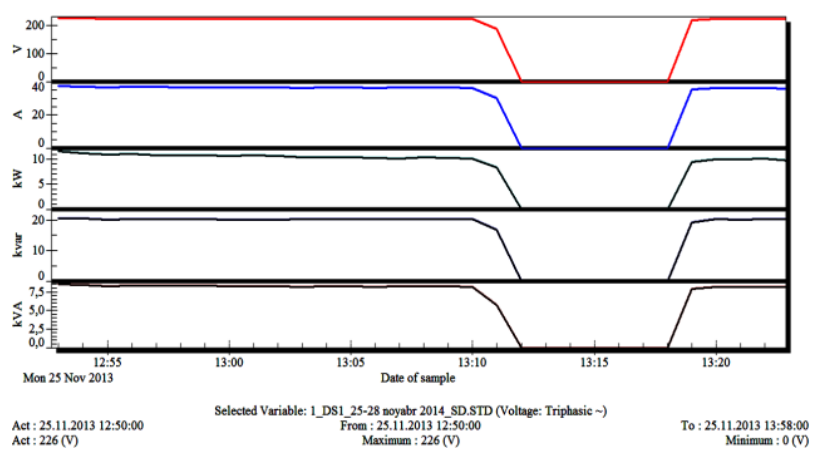

Fig. 2. Graphs of measurements of electrical parameters of an electric drive powered from a frequency converter of a plate feeder.

\section{Results and discussion}

The graph shows the indicators of the parameters of the electric drive of the feeder in the operating mode, the mode of disconnecting the feeder at the moment of 13:12 and restarting at the moment of 13:18. Restarting is carried out after a time interval equal to 8 minutes with a frequency acceleration of the drive in 1 minute according to a linear law. In this case, the supply voltage changes linearly in one stage and, accordingly, the currents increase without a surge, i.e. do not exceed the nominal value.

In Fig. 3 shows the harmonic composition of voltage and current instantaneous values up to 50 harmonics.

In Fig. 4 - change in harmonics over a period of 30 minutes.

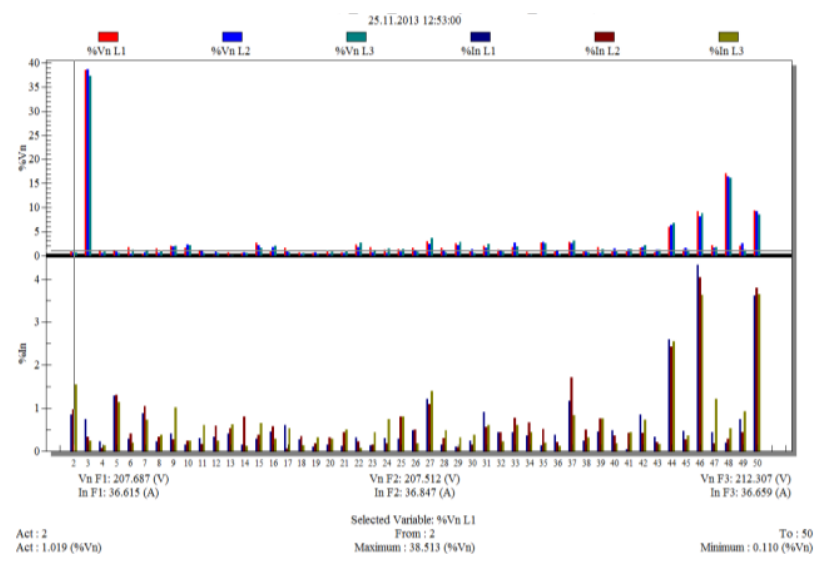

Fig. 3. Instantaneous values of harmonic composition of voltage and current up to 50 harmonics.

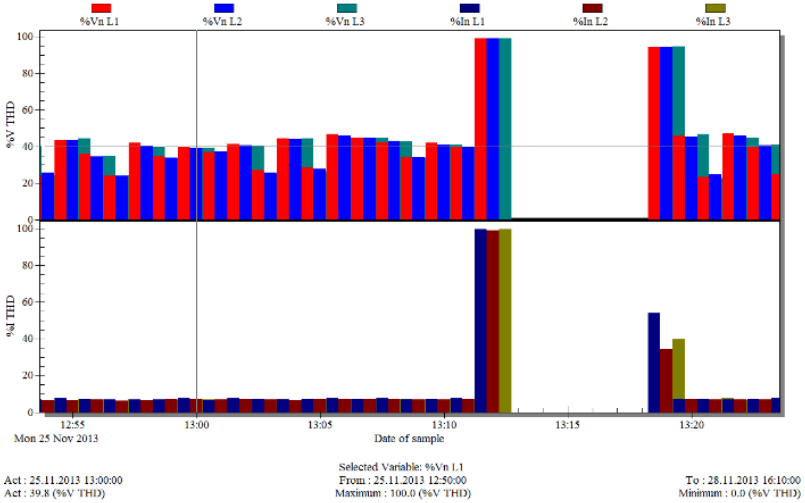

Fig. 4. Changes in harmonics of current and voltage over a period of 30 minutes.

In Fig. 5-7 - waveforms of voltage and current in the operating mode, the moment of switching off and on the plate feeder.

The output currents and voltage of the frequency converter, in contrast to the standard network, do not have a sinusoidal shape, but peaks, higher harmonics of current and voltage, a rapid change in frequency and voltage over time. This leads to an increase in the voltage on the motor insulation, increasing motor losses, vibration and noise.

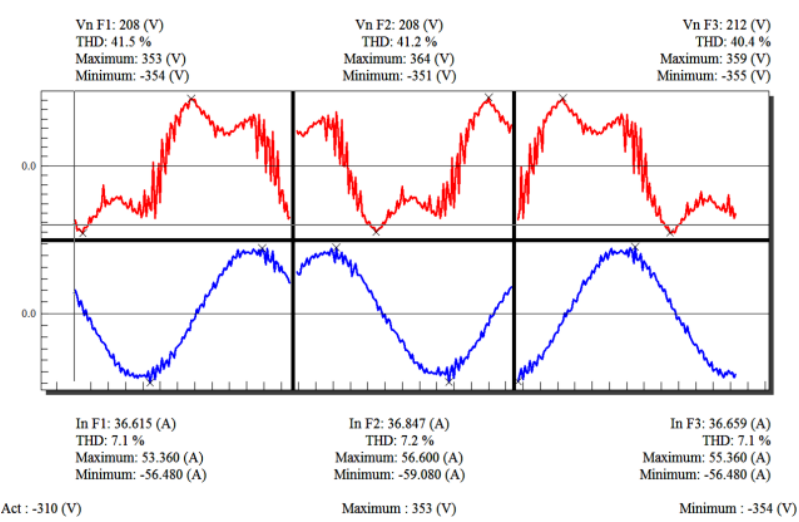

Fig. 5. Forms of voltage and current of each phase in the operating mode of the feeder.

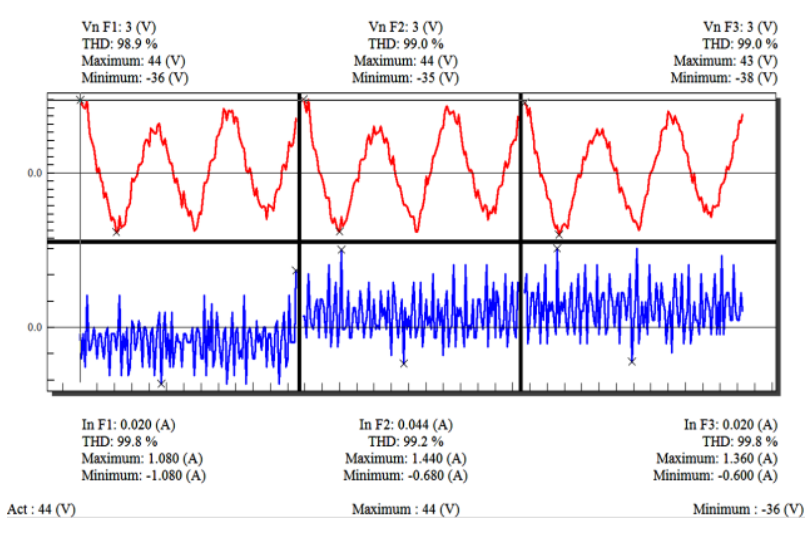

Fig. 6. Forms of voltage and current of each phase at the moment of disconnection of the feeder. 


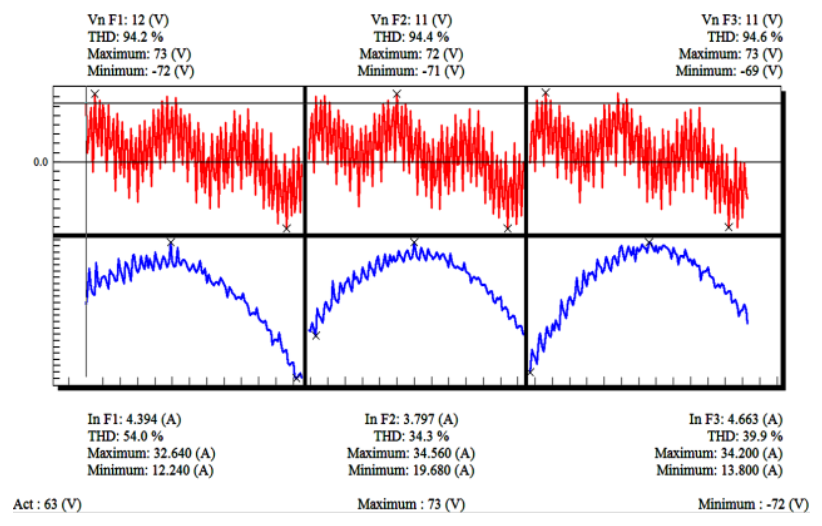

Fig. 7. Forms of voltage and current of each phase at the moment of switching on the feeder.

Different types of frequency converters, differing in operating principles, modulation and frequency switching methods, give a variation in efficiency for the same motor. It has been determined that the continuous maximum load (torque) of a drive with frequency converters depends mainly on the modulation method and the switching frequency of the frequency converter.

\section{Conclusion}

1. The basic principle of operation of a motor when powered by a frequency converter is that the maximum permissible load torque of the motor as a function of its rotor speed must give the same temperature rise in the motor as when supplied with a sinusoidal voltage of rated frequency at rated load.

2. The results of theoretical and experimental studies show that for plate feeders, speed acceleration is the most satisfying condition for a soft start and control will be carried out according to a linear law.

3 . Ensuring the stability of the operating modes of crushers and mill blocks by maintaining constant linear load of the feeder when ore is supplied, as well as the required tractive effort in steady motion.

\section{References}

1. T.S. Kamalov, M.P. Belov, V.A. Novikov, L.N. Rassudov, Automated electric drive of standard production mechanisms and technological complexes (Moscow: Academy, 576, 2007) (in Russian)

2. T.S. Kamalov, O.Z. Toirov, Control of a flowtransport system based on a frequency-controlled electric drive in the mining industry, International Scientific and Technical Conference "Energy: Management, Quality and Efficiency of Energy Use", Blagoveshchensk, 400-403 (2015) (in Russian)

3. H. Afrisal, B. Setiyono, M.F. Yusuf, R.M. Suin, O. Toirov, 7th International Conference on Information Technology, Computer, and Electrical Engineering (ICITACEE), 41-46 (2020)

10.1109/ICITACEE50144.2020.9239228
4. T.S. Kamalov, D.P. Kim, O.Z. Toirov, A.A. Shavazov, J.N. Tashpulatov, Kh.T. Tasheva, L.I. Sayfullaeva, Energy audit of the Almalyk MMC Copper Processing Plant and ways to improve energy efficiency, Uzbek journal "Problems of Informatics and Energy", 1-2 (2014) (in Russian)

5. L.S. Udut, A.Yu. Chernyshev, N.V. Gusev, Development and modeling of asynchronous electric drives with scalar control, Izvestiya vuzov. Electromechanics, 3 (539), 43-49 (2015) (in Russian) DOI: 10.17213/0136-3360-2015-343-49

6. D. Bystrov, O. Toirov, G. Mustafakulova, D. Yakubova, NISS2020: Proceedings of the 3rd International Conference on Networking, Information Systems \& Security, 54, 1-3 (2020) DOI: $10.1145 / 3386723.3387873$

7. D. Bystrov, O. Toirov, S. Giyasov, M. Taniev, U. Sardor, NISS2020: Proceedings of the 3rd International Conference on Networking, Information Systems \& Security, 49, 1-4 (2020) DOI: $10.1145 / 3386723.3387868$

8. O. Toirov, U. Mirkhonov, Overview of Compressor Installations and Issues of Their Energy saving, International Journal of Advanced Research in Science Engineering and Technology, 6 (10), 11446-11452 (2019)

9. O. Toirov, U. Mirkhonov, Principles for Controlling the Excitation of Synchronous Motors of the Compressor Installation, International, Journal of Advanced Research in Science, Engineering and Technology, 7 (5), 13876-13881 (2020)

10. A.V. Kuzmin, F.L. Maron, Handbook on the calculations of the mechanisms of hoisting-andtransport machines (Minsk: Vysh. shk., 350, 1983) (in Russian)

11. O. Toirov, A. Bekishev, S. Urokov, U. Mirkhonov, E3S Web of Conferences, 216, 01116 (2020) DOI: $10.1051 / \mathrm{e} 3$ sconf/202021601116

12. K. Alimkhodjaev, O. Toirov, M. Taniev, S. Alimkhodjaev, Addressing Issues and Possibility of Introducing Renewable Energy Sources in the Conditions of Uzbekistan, JCR, 7 (15), 17211728 (2020) DOI: 10.31838/jcr.07.15.231

13. V.P. Antsupov, M.G. Slobodyansky, A.V. Antsupov, Fundamentals of the design assessment of the durability of metallurgical equipment on the example of calculating the resource of the apron feeder of the Sinter plant, Study guide, 198 (2018) (in Russian)

14. S.G. Chirkov, V.I. Shed, T.P. Lunina, Modernization of apron feeders manufactured by JSC EZTM, aimed at increasing their operational reliability, Ferrous metallurgy, Bulletin of scientific, technical and economic information, 8 , 77-82 (2016)

15. S.G. Chirkov, A.V. Klochkov, S.A. Lagutin, Third Generation of Plate Feeder Drive Gearboxes, Intelligent Systems in Manufacturing, 2 (18), 185-187 (2011) 
16. V. Statsenko, O. Burmistenkov, T. Bila, D. Statsenko, Determining the motion character of loose materials in the system of continuous action «hopper - reciprocating plate feeder, EasternEuropean Journal of Enterprise Technologies, 2/1 (98), 21-28 (2019) DOI: 10.15587/17294061.2019.163545

17. D. Minglani, A. Sharma, H. Pandey, R. Dayal, J.B. Joshi, S. Subramaniam, A review of granular flow in screw feeders and conveyors, Powder Technology, 366, 369-381 (2020) DOI: 10.1016/j.powtec.2020.02.066

18. D. Ilic, A. Lavrinec, O. Orozovic, Simulation and analysis of blending in a conveyor transfer system, Minerals Engineering, 157, 106575 (2020) DOI: 10.1016/j.mineng.2020.106575

19. S.N. Reshetnyak, Prospects for the application of space-vector modulation in the system of electric drives of the plate feeder, Electrical and Information Complexes and Systems, 2 (2), 35-40 (2016)

20. V.N. Fashilenko, S.N. Reshetnyak, Energy efficient resonant mode of electromechanical system mining machines based on management structures with PIDcontroller, Miner's week2015: Reports of the XXIII international scientific conference, 608-612 (2015). 